\title{
Relationship between inhibition of mevalonate biosynthesis and reduced fertility in laying hens
}

\author{
R. G. Elkin and Z. Yan \\ Department of Animal Sciences, Purdue University, West Lafayette, IN 47907-1151, USA
}

\begin{abstract}
The objective of the present study was to determine the effects of inhibition of mevalonate biosynthesis on fertility and embryonic survival in laying chickens. White Leghorn hens were fed for 5 weeks with a control diet alone or a diet supplemented with one of two concentrations $(0.03$ or $0.06 \%)$ of the 3-hydroxy-3-methylglutarylcoenzyme A reductase inhibitors atorvastatin, lovastatin or simvastatin. The hens were artificially inseminated once a week and eggs that were not analysed for cholesterol content were incubated. When averaged across dietary groups and expressed as a percentage of all eggs incubated, the incidence of unfertilized eggs was $1.6 \%$ (controls), $29.1 \%$ (atorvastatin), $4.4 \%$ (lovastatin) and $7.9 \%$ (simvastatin). In contrast, with the exception of lower values for birds fed $0.06 \%$ atorvastatin, all groups had comparable hatchabilities of fertilized eggs. Hatchability of all eggs incubated was decreased in both atorvastatin groups compared with the other treatments. However, embryonic mortality of fertilized eggs was unaffected $(P>0.05)$ by diet. Compared with controls, maximum decreases in egg cholesterol of 46, 22 and $7 \%$ were obtained with atorvastatin, lovastatin and simvastatin, respectively. Although the overall correlation of egg cholesterol content with hatchability was high $(r=0.82)$, the hatch rate of eggs containing approximately $105 \mathrm{mg}$ cholesterol ranged from 0 to $67 \%$, indicating that egg cholesterol content was not the only factor influencing embryo survival. This is the first study to indicate that a mevalonate-derived product or products plays an important role in avian fertility. In addition, this work challenges the contention that virtually all of the cholesterol in chicken egg yolk is essential for embryonic development and survival.
\end{abstract}

\section{Introduction}

The cholesterol concentration of avian eggs varies among species, breeds and strains, and also with the age of birds. However, genetic selection for lower egg cholesterol content has been unsuccessful or has resulted in only slight reductions (approximately $10 \mathrm{mg}$ per egg; for review see Hargis, 1988). The inability to decrease egg cholesterol content markedly through genetic selection programmes led Hargis (1988) to hypothesize that chickens have a physiological control mechanism that causes a cessation of egg production when yolk cholesterol deposition is inadequate for embryonic survival. On the basis of this hypothesis, nutritional or pharmacological manipulation of cholesterol biosynthesis in laying hens would not be expected to cause a significant decrease in cholesterol in the yolk of non-fertilized eggs because egg production would cease when the 'critical concentration' was reached. However, there is little evidence to support this hypothesis (Griffin, 1992). Moreover, it has been suggested, on the basis of lipid metabolism studies in avian embryos, that the amount of cholesterol provided by the yolk is considerably

Received 3 August 1998. greater than the needs of the developing chick (Noble and Cocchi, 1990; Griffin, 1992).

Recent work from this laboratory with inhibitors of 3hydroxy-3-methylglutaryl-coenzyme A reductase (HMGR) also failed to support the 'critical concentration hypothesis' and cast doubt upon the presence of a cholesterol-sensing mechanism that is directly linked with reproductive function. When laying hens were administered orally with the HMGR inhibitors lovastatin (Elkin and Rogler, 1990) or PD 123244-15 (Elkin et al., 1993), there were 15 and 30\% decreases in egg cholesterol, respectively, and less effect on egg production (no change or $-18 \%$, respectively). HMGR is the rate-limiting enzyme in cholesterol synthesis and catalyses the conversion of 3-hydroxy-3-methylglutarylcoenzyme A to mevalonate (Endo, 1992). HMGR inhibitors are currently the most effective and widely used class of cholesterol-lowering drugs available for the treatment of hypercholesterolaemia in humans (Endo, 1992; Dujovne, 1997).

To examine whether further reductions in egg cholesterol could be obtained without major decreases in egg production, we investigated the physiological and biochemical consequences of treating chickens with two of the newer, more efficacious HMGR inhibitors (atorvastatin and 
simvastatin) versus lovastatin (Elkin et al., 1999). An additional objective of that study was to determine the effects of HMGR inhibition on fertility and embryonic survival in artificially inseminated laying hens; these data are reported herein.

\section{Materials and Methods}

\section{Animals and treatments}

Forty 18-month-old White Leghorn hens were obtained from the flock maintained at the Purdue University Poultry Research Center. Hens were placed individually in $30 \mathrm{~cm} \times$ $35 \mathrm{~cm} \times 45 \mathrm{~cm}$ slant-back cages in an environmentally controlled room $\left(24^{\circ} \mathrm{C}\right.$ and $16 \mathrm{~h}$ light: $8 \mathrm{~h}$ dark). Birds were assigned to one of the seven dietary treatments (see below) on the basis of both egg production and average egg mass during the 10 days immediately before the start of the experiment. Ten control hens were fed a corn-soybean mealbased layer ration (Elkin and Rogler, 1990) containing 0.06\% avice $\mathrm{l}^{\sqrt{6}}$ microcrystalline cellulose (FMC Corp., Philadelphia, PA) (diet 1), while five hens each were fed the same ration supplemented, at the expense of avicel ${ }^{\circledast}$, with $0.03 \%$ atorvastatin (diet 2), $0.06 \%$ atorvastatin (diet 3), $0.03 \%$ lovastatin (diet 4), 0.06\% lovastatin (diet 5), $0.03 \%$ simvastatin (diet 6), or $0.06 \%$ simvastatin (diet 7). The two concentrations of inhibitor were equal to approximately 30 or $60 \mathrm{mg}$ per hen per day, respectively, on the basis of a food intake of $100 \mathrm{~g}$ per bird per day (Elkin and Rogler, 1990). Atorvastatin was synthesized and provided by Parke-Davis (Roth et al., 1991). Lovastatin (Merck Sharp \& Dohme, Rahway, NJ) was prepared by extracting formulated capsules of Mevacor $^{\oplus}$ (Bocan et al., 1992), while simvastatin was provided by Merck Sharp \& Dohme. The birds were given free access to feed and water throughout the 5 week experiment, and all groups consumed between 99 and $106 \mathrm{~g}$ feed day ${ }^{-1}(P>0.05$; data not shown).

Each hen was artificially inseminated (see below) at 5 and 3 days before the start of the feeding trial and collection of hatching eggs to ensure fertility (McDaniel et al., 1993). Repeat inseminations were performed once a week using pooled semen from the same roosters.

Semen samples, collected by the massage method of Lake (1957), were obtained from several roosters maintained at the Purdue University Poultry Research Center. The undiluted samples were combined and a portion of the pooled semen was then transferred to a B-D Luer-Lok ${ }^{\circledR} 1 \mathrm{~cm}^{3}$ glass syringe (catalogue number 2190, Becton Dickinson, Rutherford, NJ) in a B-D Cornwall ${ }^{\oplus}$ continuous pipetting syringe outfit. A $5 \mathrm{~cm}$ glass insemination tube was attached to the outfit via a small piece of rubber tubing. For each hen, the cloaca was everted, the insemination tube inserted to a depth of approximately $1.5 \mathrm{~cm}$, and $0.05 \mathrm{ml}$ of pooled semen was delivered.

Eggs were collected once a day and stored at $7^{\circ} \mathrm{C}$. After removal of one egg per hen per week for cholesterol analysis (Rudel and Morris, 1973), all remaining eggs (maximum of six per hen) were incubated on the same day of each week in a Jamesway Model 252 incubator (James Manufacturing
Company, Los Angeles, CA). The incubation conditions were as follows: dry bulb temperatures of $37.8^{\circ} \mathrm{C}$ (days 0-13) and $37.2^{\circ} \mathrm{C}$ (days 14-21); wet-bulb temperatures (bulb of thermometer covered with a water-moist wick (North and Bell, 1990)) of $31.1^{\circ} \mathrm{C}$ (days $0-2$ ), $30^{\circ} \mathrm{C}$ (days $3-19$ ) and $31.1^{\circ} \mathrm{C}$ (days 20-21).

Incubated eggs were examined for fertility on day 9 of incubation and infertile eggs or eggs containing dead embryos were stored at $7^{\circ} \mathrm{C}$ until examination. On day 19 of incubation, all of the remaining eggs were transferred to hatching baskets. At the time of hatching (day 21), each chick was weighed, and all of the non-hatching eggs were examined to determine their fertility status and stage of embryonic death. Although the contents of non-hatching eggs were generally addled, those that did not contain a discernable embryo were categorized as infertile if there was no evidence of positive development (that is, presence of extra-embryonic membranes) or if the blastodisk was visible and was small and lacked organized cells.

The protocol for this study was approved by the Purdue University Animal Care and Use Committee.

\section{Statistical analysis}

The percentage of fertilized eggs, hatched eggs and dead embryos, as well as chick body weights and egg cholesterol contents, were subjected to analysis of variance using a nested factorial arrangement of treatments (Steel and Torrie, 1980). Since incubation conditions were the same each week, a split plot in time (week) was also included in the analysis, which was performed using the general linear models procedure of the $S A S^{\oplus}$ Institute (1989). Arcsin transformations were also performed on all percentage data. However, since the statistical patterns were similar for both transformed and untransformed results, only the latter are presented. Individual treatment differences were tested by Duncan's multiple range test (Steel and Torrie, 1980). Single degree of freedom linear contrasts (Steel and Torrie, 1980) were also performed to make comparisons between the HMGR inhibitors and to compare them with the control treatment. Differences at $P \leq 0.05$ were considered significant. The curve fitter procedure of SlideWrite ${ }^{\circledast}$ Plus Version 3 for Windows ${ }^{\mathrm{TM}}$ (Advanced Graphics Software, Inc., Carlsbad, CA), which applies linear least squares regression analysis, was used to determine the relationship between hatchability per week of all eggs incubated and egg cholesterol values.

\section{Results}

\section{Fertility}

Although semen characteristics were not determined in the pooled samples used to artificially inseminate the hens, the overall fertility rate of $98.4 \%$ in the control hens indicates that sperm quantity and quality were consistently high (Fig. 1a). In contrast, when averaged over the 5 week study, the percentage of fertilized eggs was significantly reduced, in a concentration-dependent manner, in the atorvastatin 


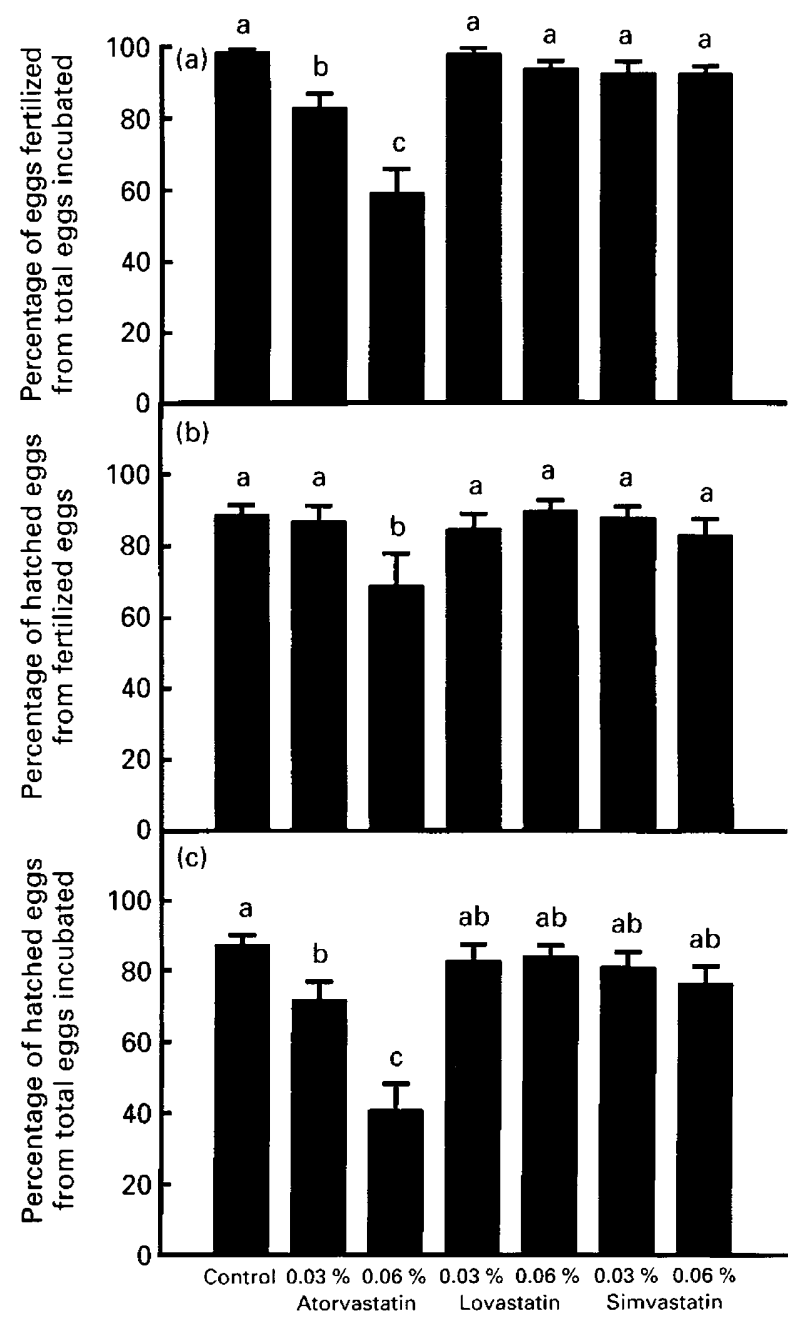

Fig. 1. Effect of 3-hydroxy-3-methylglutaryl-coenzyme A reductase (HMGR) inhibitors on fertility and hatchability of chicken eggs. (a) Percentage of eggs fertilized from total eggs incubated, (b) hatchability of fertilized eggs, (c) hatchability of total eggs incubated. The total number of eggs incubated from control hens $(n=10)$ and hens in each HMGR inhibitor-treated group ( $n=5$ in each group) during the 5 week study were: control, $251 ; 0.03 \%$ atorvastatin, 110 ; $0.06 \%$ atorvastatin, $98 ; 0.03 \%$ lovastatin, $133 ; 0.06 \%$ lovastatin, 125 ; $0.03 \%$ simvastatin, 116 ; and $0.06 \%$ simvastatin, 114 . Values are mean \pm SEM. Within a classification (percentage fertilized, hatchability of fertilized eggs, and hatchability of total eggs incubated), bars with common letters are not significantly different $(P>0.05)$.

treatments compared with the other groups. Moreover, the incidence of unfertilized eggs, expressed as a percentage of all eggs incubated and averaged across concentration, was $1.6 \%$ (controls), $29.1 \%$ (atorvastatin), $4.4 \%$ (lovastatin) and $7.9 \%$ (simvastatin) (data not shown). Single degree of freedom linear contrasts revealed the following significant differences for percentage fertility: atorvastatin < control, atorvastatin < lovastatin, atorvastatin < simvastatin, and simvastatin < control. In addition to a significant diet effect, there was a significant diet $\times$ week interaction. In contrast to all other treatment groups, the fertility of hens fed $0.06 \%$ atorvastatin decreased markedly between weeks 2 and 3, and remained low for the remainder of the study (data not shown).

\section{Hatchability and egg cholesterol content}

Hatchability of fertilized eggs was significantly affected by diet and week. However, with the exception of birds fed $0.06 \%$ atorvastatin, all groups had comparable overall values (Fig. 1b). Single degree of freedom linear contrasts revealed the following significant differences for hatchability of fertilized eggs: atorvastatin < control, atorvastatin < lovastatin, and atorvastatin $<$ simvastatin.

Significant diet, week, and $\operatorname{diet} \times$ week interactions were observed for hatchability of total eggs, although no significant treatment effects on hatchability were noted until the third week of the experiment (Table 1). At that time, the hatchability of all eggs from hens fed $0.06 \%$ atorvastatin decreased to $0 \%$ (from $67 \%$ in week 2); during weeks 4 and 5 , the values recovered to approximately $20 \%$. By week 5 , hens fed $0.03 \%$ atorvastatin also exhibited significantly decreased hatchability of all eggs incubated compared with all other treatment groups. The following significant single degree of freedom linear contrasts were observed for hatchability of all eggs during weeks 3, 4 and 5: atorvastatin < control, atorvastatin < lovastatin, and atorvastatin < simvastatin.

Compared with controls, all of the HMGR inhibitortreated groups exhibited decreased overall hatchabilities of total eggs incubated (Fig. 1c). However, significant differences were noted only for the atorvastatin groups. When averaged across dietary amounts, the hatchability of all eggs was $56.3,83.4$ and $78.7 \%$ for hens fed atorvastatin, lovastatin and simvastatin, respectively, compared with the control value of $87.3 \%$. Single degree of freedom linear contrasts revealed the following significant differences: atorvastatin < control, atorvastatin < lovastatin, and atorvastatin $<$ simvastatin.

There were no differences $(P>0.05)$ in egg cholesterol content (mg per egg) among treatments at day 0 of the study (control, 196.6; $0.03 \%$ atorvastatin, $203.2 ; 0.06 \%$ atorvastatin, $191.9 ; 0.03 \%$ lovastatin, $195.7 ; 0.06 \%$ lovastatin, $197.8 ; 0.03 \%$ simvastatin, $189.7 ; 0.06 \%$ simvastatin, 191.1). However, significant decreases in egg cholesterol contents were noted in both groups fed atorvastatin after only 7 days of treatment (161.7 and $149.7 \mathrm{mg}$ per egg, respectively, versus $198.3 \mathrm{mg}$ per egg for controls; Table 1). By week 2, eggs from the hens fed 0.03 and $0.06 \%$ atorvastatin contained 27 and $45 \%$ less total cholesterol than those from control hens (141.1 and 105.3 versus $193.1 \mathrm{mg}$ per egg, respectively). These decreases were maintained throughout the remainder of the study; by week 5 , cholesterol contents of $137.2 \mathrm{mg}$ per egg $(0.03 \%$ atorvastatin) and $107.9 \mathrm{mg}$ per egg ( $0.06 \%$ atorvastatin) were observed. The latter value represented a $46 \%$ decrease in cholesterol content versus the control value $(201.5 \mathrm{mg}$ per egg) and was due to a $19 \%$ decrease in yolk mass combined with a 35\% decrease in cholesterol (g per yolk) (Elkin et al., 1999). Simvastatin also decreased egg cholesterol content $(P<0.05)$, but to a lesser extent than atorvastatin. Compared with controls, the maximum decrease in cholesterol per egg of $22 \%$ was observed in hens fed $0.06 \%$ simvastatin $(158.0$ 
Table 1. Hatchability and cholesterol content of eggs from control hens and hens fed 3-hydroxy-3-methylglutaryl-coenzyme A reductase inhibitors

\begin{tabular}{|c|c|c|c|c|c|c|}
\hline Treatment & $\begin{array}{c}\text { Percentage } \\
\text { of diet }\end{array}$ & Week 1 & Week 2 & Week 3 & Week 4 & Week 5 \\
\hline Atorvastatin & 0.03 & $69.2 \pm 16.1^{\text {a }}(26)$ & $79.0 \pm 8.4^{a}(19)$ & $63.6 \pm 10.1^{\mathrm{a}}(22)$ & $91.3 \pm 5.6^{a}(23)$ & $55.0 \pm 7.6^{\mathrm{b}}(20)$ \\
\hline Atorvastatin & 0.06 & $85.2 \pm 7.4^{\mathrm{a}}(27)$ & $66.7 \pm 13.3^{a}(15)$ & $0.0^{\mathrm{b}}(20)$ & $20.0 \pm 5.6^{b}(20)$ & $18.8 \pm 7.6^{c}(16)$ \\
\hline Lovastatin & 0.03 & $93.3 \pm 4.5^{a}(30)$ & $76.9 \pm 14.7^{\mathrm{a}}(26)$ & $72.0 \pm 10.2^{a}(25)$ & $84.6 \pm 11.6^{a}(26)$ & $84.6 \pm 11.6^{a}(26)$ \\
\hline \multirow[t]{2}{*}{ Simvastatin } & 0.06 & $75.0 \pm 14.7^{\mathrm{a}}(24)$ & $87.0 \pm 9.8^{a}(23)$ & $66.7 \pm 14.4^{\mathrm{a}}(18)$ & $82.6 \pm 7.7^{a}(23)$ & $69.2 \pm 8.9^{\mathrm{ab}}(26)$ \\
\hline & & \multicolumn{5}{|c|}{ Cholesterol $^{\dagger}$ (mg per egg) } \\
\hline Control & - & $198.3 \pm 4.3^{a}$ & $193.1 \pm 3.9^{a}$ & $198.8 \pm 4.3^{\mathrm{a}}$ & $199.7 \pm 3.0^{\mathrm{a}}$ & $201.5 \pm 5.8^{\mathrm{a}}$ \\
\hline Atorvastatin & 0.03 & $161.7 \pm 5.5^{b c}$ & $141.1 \pm 3.3^{c}$ & $143.7 \pm 3.3^{c}$ & $134.4 \pm 2.2^{\mathrm{c}}$ & $137.2 \pm 3.8^{d}$ \\
\hline Simvastatin & 0.06 & $188.7 \pm 9.1^{\mathrm{ab}}$ & $170.8 \pm 3.0^{b}$ & $166.0 \pm 4.6^{\mathrm{b}}$ & $170.4 \pm 7.0^{b}$ & $158.0 \pm 2.7^{\mathrm{cd}}$ \\
\hline
\end{tabular}

*Values are means \pm SEM for eggs incubated from $\operatorname{control}(n=10)$ or treated ( $n=5$ in each group) hens. Hatchability was calculated as follows: (number of live chicks obtained on day 21 of incubation/number of eggs incubated) $\times 100$. The number of eggs incubated is shown in parentheses.

'Values are means \pm SEM for one egg per hen per week that was not incubated, thus, $n=10$ (control hens) or $n=5$ (treated hens).

$\cdots-W i t h i n$ a column, means with different superscripts are significantly different $(P<0.05)$.

versus $201.5 \mathrm{mg}$, respectively). Lovastatin was the least efficacious of the three HMGR inhibitors, as evidenced by a maximum decrease in egg cholesterol of only $7 \%$ compared with controls (186.9 versus $201.5 \mathrm{mg}$ per egg, respectively).

Although the association between egg cholesterol content and hatchability of all eggs was high $(r=0.82)$, markedly different hatchability rates were observed in eggs containing similar amounts of total cholesterol (Fig. 2). In particular, the hatch rate of eggs containing approximately $105 \mathrm{mg}$ cholesterol, laid by hens fed $0.06 \%$ atorvastatin, was quite variable $(66.7 \%$, week $2 ; 0 \%$, week $3 ; 20.0 \%$, week 4 ; and $18.8 \%$, week 5; Table 1). These results indicate that egg cholesterol content is not the only factor that influences hatchability.

\section{Embryonic mortality}

Embryonic death occurred in $11.2 \%$ (controls), $14.7 \%$ (atorvastatin), $12.3 \%$ (lovastatin) and 13.5\% (simvastatin) of all eggs incubated, and there were no significant effects due to dietary treatment (data not shown). Moreover, the temporal pattern of embryonic mortality in all groups (Fig. 3) was fairly typical of a commercial setting (North and Bell, 1990); most deaths occurred early (days 1-7) or late (days 15-21) in development or during hatching, which was denoted as pipped (beak penetrated the eggshell but chick did not hatch). When calculated as a relative percentage of all embryonic deaths, embryos from hens fed atorvastatin showed the highest mortality during days $1-7$, while embryos from hens fed $0.06 \%$ lovastatin or simvastatin had the highest percentage of pipped embryos.

Embryonic death in the $0.03 \%$ and $0.06 \%$ atorvastatin groups, which had the lowest hatch rates (Fig. 1c), accounted for only 31 and $39 \%$, respectively, of all non-hatching eggs (data not shown). In the other groups, eggs containing dead embryos accounted for a higher percentage of all eggs that were incubated but did not hatch $(88,87,60,59$ and $67 \%$ in the control, $0.03 \%$ lovastatin, $0.06 \%$ lovastatin, $0.03 \%$ simvastatin and $0.06 \%$ simvastatin treatments, respectively).

\section{Chick body weights}

When averaged over all 5 weeks, the body weight of chicks from HMGR inhibitor-fed hens did not differ from those of the control group (Table 2). However, there was a significant difference between the $0.03 \%$ atorvastatin and $0.03 \%$ lovastatin groups ( $41.4 \mathrm{~g}$ versus $44.9 \mathrm{~g}$, respectively). Although chicks from hens fed $0.06 \%$ atorvastatin were much smaller than control chicks during weeks 2,4 and 5 (average body weights of 39.3, 36.2 and $39.8 \mathrm{~g}$ versus 44.2, 43.5 and $45.0 \mathrm{~g}$, respectively), the overall average body weight $(42.2 \mathrm{~g})$ was not significantly different from that of the control birds ( $44.3 \mathrm{~g}$ ). Notably, 23 of 40 chicks obtained from hens fed $0.06 \%$ atorvastatin hatched during week 1 and these chicks were considerably larger ( $44.9 \mathrm{~g}$ ) than those that hatched during subsequent weeks. No significant single degree of freedom linear contrasts were observed.

\section{Discussion}

The present study is the first to indicate that a mevalonatederived product or products plays an essential role in avian fertility. Although the specific mevalonate metabolite 


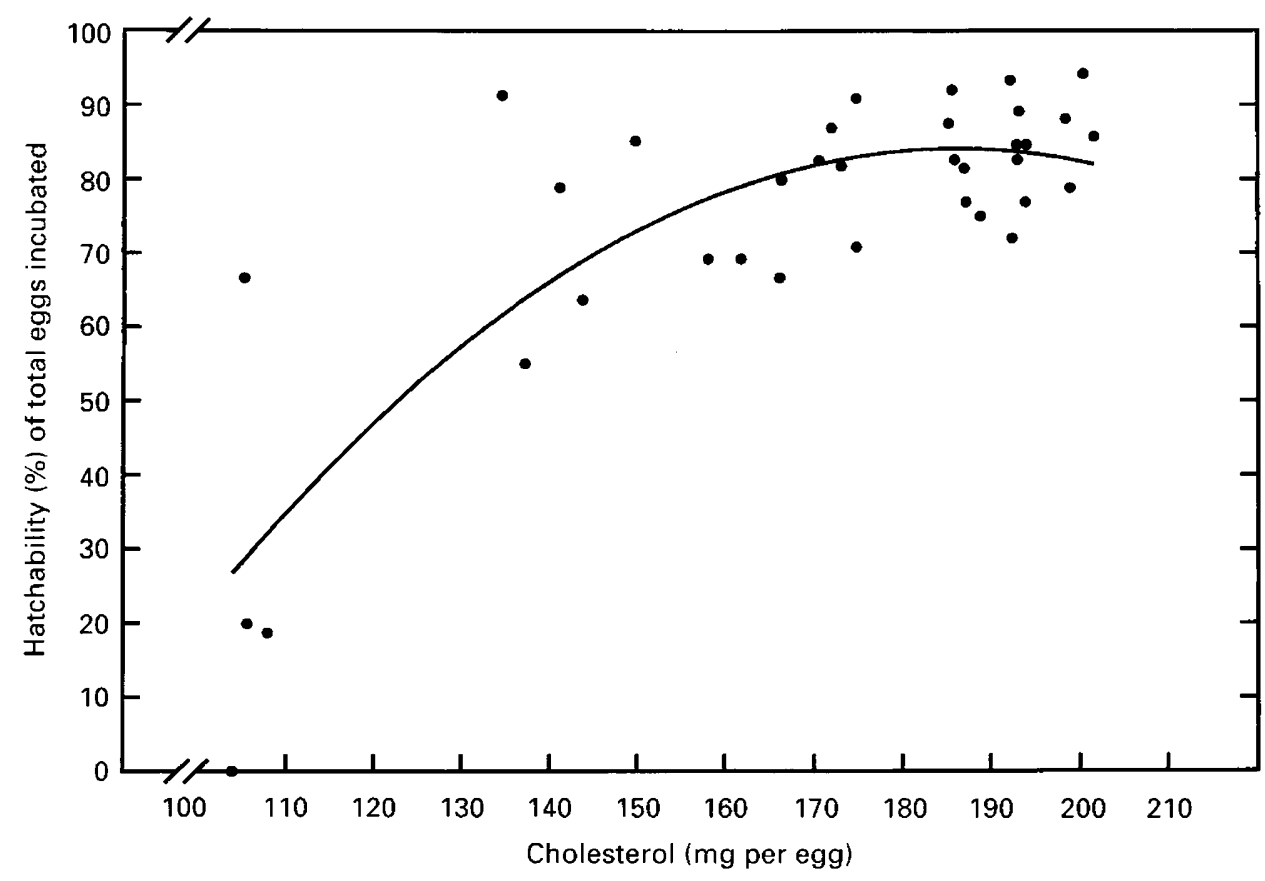

Fig. 2. The relationship between hatchability, as a percentage of total eggs incubated, and egg cholesterol content. Hatchability per week and egg cholesterol values from Table 1 were plotted and each data point represents the mean of either ten control hens or five 3-hydroxy-3-methylglutarylcoenzyme A reductase inhibitor-treated hens. $y=-211.234+3.178 x-0.009 x^{2} ; r=0.82$.

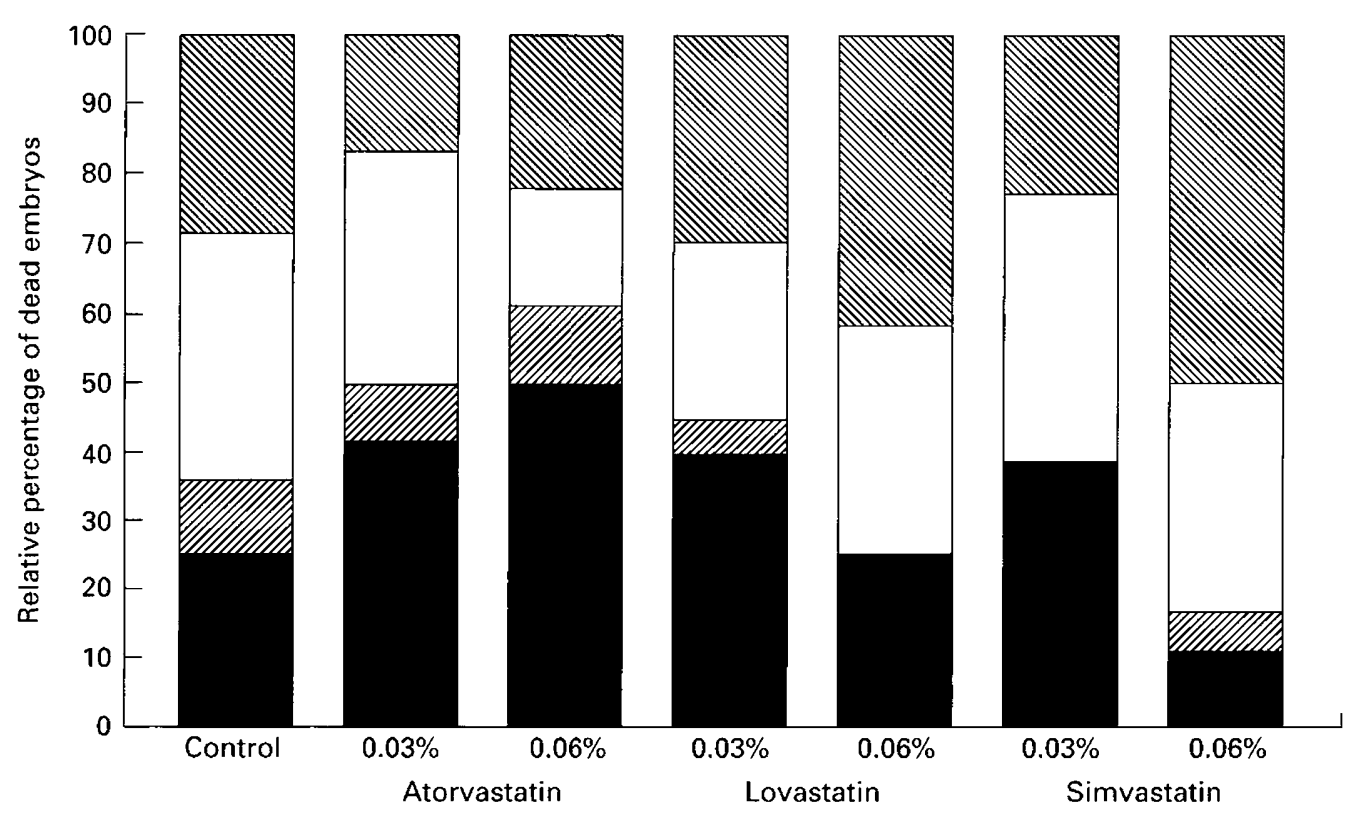

Fig. 3. Temporal profiles of embryonic mortality in control hens and hens treated with 3-hydroxy-3methylglutaryl-coenzyme A reductase (HMGR) inhibitors. The relative percentage of dead embryos at the early (days $1-7, \square$ ), mid- (days 8-14, $\mathbb{Z}$ ) and late (days 15-21, $\square$ ) stages of development during the 5 week study are shown, as well as those whose beaks penetrated the eggshells but did not hatch (pipped, $\mathbb{P}$ ) (thus $n=1$ per treatment). The total number of non-hatching fertilized eggs from the ten control hens and the five hens in each HMGR inhibitor-treated group were: control, $28 ; 0.03 \%$ atorvastatin, $12 ; 0.06 \%$ atorvastatin, 18 ; $0.03 \%$ lovastatin, $20 ; 0.06 \%$ lovastatin, $12 ; 0.03 \%$ simvastatin, $13 ;$ and $0.06 \%$ simvastatin, 18 . 
Table 2. Body weight (g) of chicks hatched from eggs from control hens and hens fed 3-hydroxy-3-methylglutaryl-coenzyme A reductase inhibitors

\begin{tabular}{|c|c|c|c|c|c|c|c|}
\hline Treatment & $\begin{array}{c}\text { Percentage } \\
\text { of diet }\end{array}$ & Week 1 & Week 2 & Week 3 & Week 4 & Week 5 & Overall \\
\hline Control & - & $44.7 \pm 0.5^{\mathrm{a}}(52)$ & $44.2 \pm 0.6^{\mathrm{a}}(41)$ & $44.4 \pm 0.6^{a}(41)$ & $43.5 \pm 0.5^{3}(49)$ & $45.0 \pm 0.7^{\mathrm{a}}(36)$ & $44.3 \pm 0.2^{\mathrm{ab}}(219)$ \\
\hline Atorvastatin & 0.06 & $44.9 \pm 0.8^{\mathrm{a}}(23)$ & $39.3 \pm 0.9^{b}(10)$ & $-(0)$ & $36.2 \pm 1.3^{b}(4)$ & $39.8 \pm 1.9^{a}(3)$ & $42.2 \pm 0.7^{\mathrm{ab}}(40)$ \\
\hline Lovastatin & 0.03 & $46.7 \pm 0.7^{\circ}(28)$ & $44.0 \pm 0.6^{a}(20)$ & $44.4 \pm 0.8^{\mathrm{a}}(18)$ & $44.7 \pm 0.5^{\mathrm{a}}(22)$ & $44.2 \pm 0.8^{\mathrm{a}}(22)$ & $44.9 \pm 0.3^{a}(110)$ \\
\hline Lovastatin & 0.06 & $43.3 \pm 0.9^{\mathrm{a}}(23)$ & $42.9 \pm 0.5^{a}(19)$ & $43.6 \pm 0.8^{\mathrm{a}}(21)$ & $43.2 \pm 0.6^{\mathrm{a}}(20)$ & $43.1 \pm 0.8^{\mathrm{a}}(22)$ & $43.2 \pm 0.3^{\mathrm{ab}}(105)$ \\
\hline
\end{tabular}

Values are means \pm SEM for all chicks obtained from control $(n=10)$ or treated $(n=5$ in each group) hens. Number of chicks is shown in parentheses.

${ }^{a b}$ Within a column, means with different superscripts are significantly different $(P<0.05)$.

involved remains to be identified, these results show that the low hatchability rates (as a percentage of total eggs incubated) in hens treated with atorvastatin, a potent HMGR inhibitor, were primarily due to a high incidence of unfertilized eggs combined with a significantly decreased hatch rate of fertilized eggs $(0.06 \%$ dosage; Fig. 1 atorvastatin). This finding is in direct contrast to the lack of adverse effects of atorvastatin on fertility and reproduction in rodents reported by Dostal et al. (1996). Female rats were gavaged daily with either 20,100 or $225 \mathrm{mg}$ atorvastatin per $\mathrm{kg}$ body weight for 2 weeks before mating (with untreated males in a 1:1 ratio for a maximum of 19 days), during mating, and until implantation (day 7 of gestation). Fertility indices ((number of pregnant animals/number of spermpositive animals) $\times 100$ ) and the number of viable litters were not significantly different $(P>0.05)$ between control and treated rats. Fertility indices ranged from 92 to $100 \%$, while the percentage of females with viable litters ranged from 77 to $83 \%$ (Dostal et al., 1996).

In spite of an association between hatchability and egg cholesterol content, there was tremendous variability in the hatchability rate of eggs that contained approximately $105 \mathrm{mg}$ cholesterol $(0.06 \%$ atorvastatin treatment, weeks $2-5)$. This indicates that egg cholesterol content is not the only factor that influences embryonic survival. Moreover, the present work challenged the hypothesis (Hargis, 1988) that virtually all of the cholesterol in chicken egg yolk (213 $\mathrm{mg}$ in a 16.6 g yolk; United States Department of Agriculture, 1989) is required for embryonic viability. Conversely, the results of the present study support the hypothesis (Noble and Cocchi, 1990; Griffin, 1992), on the basis of lipid metabolism studies, that egg yolk cholesterol may be more of an excess waste product than an essential component required by embryonic tissues.

In addition to failure of fertilization, embryonic mortality is the other major factor that affects the hatchability rate of eggs. Although mortality was slightly higher in embryos from HMGR inhibitor-fed hens compared with controls, the differences were not significant. Nevertheless, the possibility that these drugs are transferred to the egg and cause embryotoxicity cannot be excluded and requires further investigation.

Although circulating concentrations of steroid hormones derived from cholesterol were not determined in the hens in the present study, it is possible that plasma oestrogen or progesterone concentrations were attenuated as a result of HMGR inhibition. However, since all HMGR inhibitortreated groups were able to maintain overall (over 5 weeks) egg laying rates that were at least $81 \%$ of the control value of $85.1 \%$ (Elkin et al., 1999), their ability to synthesize sex steroid hormones was probably not compromised to a significant extent.

The size of a newly hatched chick is directly related to the size of the egg from which it hatches (North and Bell, 1990). Thus, the decrease in chick body weights starting at week 2 in the hens fed $0.06 \%$ atorvastatin appeared to be related directly to parallel decreases in yolk and egg masses (reported in Elkin et al., 1999).

Severe developmental defects in mammalian vertebrates (for example, holoprosencephaly; Porter et al., 1996) have been associated with perturbations in cholesterol biosynthesis (reviewed by Farese and Herz, 1998). However, no treatmentrelated embryonic malformations or deformities in live chicks were observed in the present study. Moreover, there are no reports on the teratogenicity of HMGR inhibitors in avians. In contrast, teratogenic effects in mammals have been observed for lovastatin and fluvastatin, whereas simvastatin and atorvastatin are non-teratogenic (reviewed by Dostal et al., 1994).

Although the mechanism of the atorvastatin-associated infertility observed in the present study may involve impairment of sperm storage, oviductal transport and sperm-egg binding, it is hypothesized that defective spermegg binding alone may explain this observation. This is supported by a number of observations. Firstly, both $\mathrm{O}$ - and $N$-linked oligosaccharides are known to play a role in avian sperm-egg binding (Howarth, 1992). In addition, chicken zona pellucida glycoprotein $C$, a perivitelline membrane protein and the chicken homologue of the mammalian sperm receptor (zona pellucida glycoprotein 3), is $N$-glycosylated (Waclawek et al., 1998). Dolichol, a mevalonate-derived product, functions (via dolichyl-phosphate) as an oligosaccharide carrier in the assembly of the carbohydrate chains of $N$-linked glycoproteins (Kornfeld and Kornfeld, 1985). Finally, the cellular depletion of mevalonate decreases both the synthesis of dolichyl-phosphate and the rate of $N$-linked 
glycosylation in cultured human melanoma cells (Carlberg et al., 1996). Therefore, it is speculated that the marked decrease in fertility in laying hens fed $0.06 \%$ atorvastatin may be due to a decrease in $\mathrm{N}$-glycosylation of chicken zona pellucida glycoprotein C, which results in impaired sperm-egg binding. Studies are currently underway to address this possibility.

The authors are grateful to Roger Newton, formerly of ParkeDavis Pharmaceutical Research, for providing the HMGR inhibitors. Appreciation is also extended to Mark Einstein for conducting the statistical analyses, to Ken Wolber for his excellent managerial supervision of the laying hens and their progeny, and to Scotti Hester for her helpful comments on the manuscript.

\section{References}

Bocan TMA, Ferguson E, McNally W, Uhlendorf PD, Mueller SB, Dehart P, Sliskovic DR, Roth BD, Krause BR and Newton RS (1992) Hepatic and nonhepatic sterol synthesis and tissue distribution following administration of a liver selective HMG-CoA reductase inhibitor, CI-981: comparison with selected HMG-CoA reductase inhibitors Biochimica Biophysica Acta 1123 133-144

Carlberg MA, Dricu A, Blegen H, Wang M, Hjertman M, Zickert P, Höög A and Larsson $O$ (1996) Mevalonic acid is limiting for $N$-linked glycosylation and translocation of the insulin-like growth factor- 1 receptor to the cell surface Journal of Biological Chemistry 271 17 453-17462

Dostal LA, Schardein JL and Anderson JA (1994) Developmental toxicity of the HMG-CoA reductase inhibitor, atorvastatin, in rats and rabbits Teratology $50387-394$

Dostal LA, Whitfield LR and Anderson JA (1996) Fertility and general reproduction studies in rats with the HMG-CoA reductase inhibitor atorvastatin Fundamental and Applied Toxicology 32 285-292

Dujovne CA (1997) New lipid lowering drugs and new effects of old drugs Current Opinion in Lipidology 8 362-368

Elkin RG and Rogler JC (1990) Reduction of the cholesterol content of eggs by the oral administration of lovastatin to laying hens Journal of Agricultural and Food Chemistry 38 1635-1641

Elkin RG, Freed MB, Kieft KA and Newton RS (1993) Alteration of egg yolk cholesterol content and plasma lipoprotein profiles following administration of a totally synthetic HMG-CoA reductase inhibitor to laying hens Journal of Agricultural and Food Chemistry 41 1094-1101

Elkin RG, Yan Z, Zhong Y, Donkin SS, Buhman KK, Story JA, Turek JJ,
Porter RE, Anderson M, Homan R and Newton RS (1999) Select 3hydroxy-3-methylglutaryl-coenzyme A reductase inhibitors vary in their ability to reduce egg yolk cholesterol levels in laying hens through alteration of hepatic cholesterol biosynthesis and plasma VLDL composition Journal of Nutrition 129 1010-1019

Endo A (1992) The discovery and development of HMG-CoA reductase inhibitors Journal of Lipid Research 33 1569-1582

Farese RV and Herz J (1998) Cholesterol metabolism and embryogenesis Trends in Genetics 14 115-120

Griffin HD (1992) Manipulation of egg yolk cholesterol: a physiologist's view World's Poultry Science fournal 48 101-112

Hargis PS (1988) Modifying egg yolk cholesterol in the domestic fowl: a review World's Poultry Science Journal 44 17-29

Howarth B (1992) Carbohydrate involvement in sperm-egg interaction in the chicken Journal of Receptor Research 12 255-265

Kornfeld $\mathbf{R}$ and Kornfeld $\mathbf{S}$ (1985) Assembly of asparagine-linked oligosaccharides Annual Review of Biochemistry 54 631-664

Lake PE (1957) Fowl semen as collected by the massage method Journal of Agricultural Science (Cambridge) 49 120-126

McDaniel CD, Balog JM, Freed M, Elkin RG, Wellenreiter RH, Kuczek T and Hester PY (1993) Response of layer breeders to dietary acetylsalicylic acid. 3. Effects on fertility and hatchability of embryos exposed to control and elevated incubation temperatures Poultry Science 72 1100-1108

Noble RC and Cocchi M (1990) Lipid metabolism and the neonatal chicken Progress in Lipid Research 29 107-140

North MO and Bell DD (1990) Commercial Chicken Production Manual 4th Edn Van Nostrand Reinhold, New York

Porter JA, Young KE and Beachy PA (1996) Cholesterol modification of hedgehog signaling proteins in animal development Science 274 255-259

Roth BD, Blankley CI, Chucholowski AW, Ferguson E, Hoefle ML, Otwine DF, Newton RS, Sekerke CS, Sliskovic DR, Stratton CD and Wilson MW (1991) Inhibitors of cholesterol biosynthesis. 3. Tetrahydro-4-hydroxy-6-[2(1H-pyrrol-1-yl)ethyl]-2H-pyran-2-one inhibitors of HMG-CoA reductase. 2. Effects of introducing substituents at positions three and four of the pyrrole nucleus Journal of Medicinal Chemistry 34 357-366

Rudel LL and Morris MD (1973) Determination of cholesterol using o-phthalaldehyde Journal of Lipid Research 14 364-366

SAS (1989) SAS/STAT $\odot$ User's Guide pp 891-996 Version 6, 4th Edn, Vol. 2 SAS Institute Inc., Cary, $\mathrm{NC}$

Steel RGD and Torrie JH (1980) Principles and Procedures of Statistics: $A$ Biometrical Approach 2nd Edn. McGraw-Hill, New York

United States Department of Agriculture (1989) Composition of Foods: Dairy and Egg Products Agriculture Handbook No. 8-1 p 139. Agricultural Research Service, Washington, DC

Waclawek M, Foisner R, Nimpf J and Schneider WJ (1998) The chicken homologue of the zona pellucida protein- 3 is synthesized by granulosa cells Biology of Reproduction 59 1230-1239 